\title{
The Impact of Cosmetic Surgery on Women's Marital Satisfaction and Self-Concept
}

\author{
Nazanin Rita Davai ${ }^{1}$, Abdoljalil Kalantar-Hormozi ${ }^{2}$, Kamran Ganji ${ }^{3 *}$, \\ Ali Abbaszadeh-Kasbi ${ }^{4}$
}

1. Department of Clinical Psychology, Private Practice, Tehran, Iran;

2. Department of Plastic and Craniofacial Surgery, Medical College, Shahid Beheshti University of Medical Science, 15 Khordad Hospital, Tehran, Iran;

3. Department of Psychology, Malayer Branch, Islamic Azad University, Malayer, Iran;

4. School of Medicine, Tehran University of Medical Sciences, Tehran, Iran

*Corresponding Author:

Kamran Ganji,

Associate Professor of Department of Psychology,

Malayer Branch, Islamic Azad University, Malayer, Iran.

Tel: $+98-21-88901108$

Fax: +98-21-88909193

Email: Ganjikamran@yahoo.com

Received: November 30, 2017

Revised: July 5, 2018

Accepted: July 25, 2018

\begin{abstract}
\section{BACKGROUND}

Today, cosmetic surgery is one of the most common procedures worldwide, and its use is increasing. This study aimed to identify the impact of cosmetic surgery on married women's marital satisfaction and self-concept.

\section{METHODS}

From January $1^{\text {st }}, 2015$ to June $6^{\text {th }}, 2015$, 44 married women operated in a plastic surgery clinic or seeking for a cosmetic surgery and 55 non-applicants as general population were enrolled. ENRICH marital satisfaction questionnaire and Rogers' Self-concept Inventory were used to compare groups.

\section{RESULTS}

Operated applicants revealed a significant higher level of satisfaction in comparison with other groups regarding personality, conflict and leisure. Compared to control group, the surgical group had significantly higher satisfaction in marital and familial relationship, friendship, and financial management.

\section{CONCLUSION}

It can be drawn that expectation for postoperative positive outcome probably is an important factor affecting high level of marital satisfaction in cosmetic surgery applicants. Furthermore, the self-concept is significant predictor of applying for cosmetic surgery.

\section{KEYWORDS}

Marital satisfaction; Self-concept; Women, Cosmetic surgery

Please cite this paper as:

Davai NR, Kalantar-Hormozi A, Ganji K, Abbaszadeh-Kasbi A. The Impact of Cosmetic Surgery on Women's Marital Satisfaction and SelfConcept. World J Plast Surg 2018;7(3):337-344. doi: 10.29252/wips.7.3.337.

\section{INTRODUCTION}

Today, cosmetic surgery is one of the most common procedures worldwide, and its use is increasing. ${ }^{1}$ The frequency of plastic surgery in 2005 was 10.2 million in United States and increased to 11.7 million in $2007 . .^{2,3}$ In Iran, there has been about 70 percent increase in demand for cosmetic surgery since 1990s, and this rate has an increasing trend. ${ }^{4}$ Marital satisfaction has been defined as objective feeling of happiness, satisfaction and joy experienced by the couples, when considering all aspects of marriage. Marital 
satisfaction is an attitudinal variable; therefore, it is regarded as couple's personal attributes. One of the variables affecting the association between cosmetic surgery and marital satisfaction is physical attractiveness. ${ }^{4}$

It was shown that factors predicting the likelihood of demand for unnecessary (nonindicated) cosmetic surgery and showed that the lower levels of physical attractiveness (selfevaluation) predict the high demand for cosmetic surgery; therefore, it seems that one of the factors that the married cosmetic surgery applicants follow is enhancing physical attractiveness (this probably justifies the demand for women cosmetic surgeries including breast surgery and the like) and promoting marital satisfaction. ${ }^{5}$

Those who feel they are not physically attractive are more likely to undergo cosmetic surgeries. This idea supports the idea that failure to achieve the social ideals of attractiveness results in higher levels of physical dissatisfaction and finally leads to cosmetic surgeries. It ought to be noted that higher levels of physical satisfaction will not be achieved by these people after the surgery, if these demands are due to these individuals' low self-estimate. This reveals the critical role of another variable mediating the impact of cosmetic surgery on expected consequence (i.e. self-concept).

Self-concept is a dynamic system of beliefs, values, sentiments, talents and capabilities. Selfconcept refers to one's self-assessment. This is an individual's subjective assessment of its own characteristics which may be positive or negative. Positive self-concept indicates that the person accept himself as a person having strengths and weaknesses, leading to his enhance self-confidence in social relations. Negative selfconcept reflects the feelings of worthlessness, incompetence and disability. ${ }^{6}$

Self-concept is an overall perception of what we are. ${ }^{7}$ Self-concept is defined as one's image of himself including actual experiences and the interpretation of these experiences. In general, self-concept is a multi-dimensional and multi-level concept. Body image and selfesteem are studied as the most vital aspects of self-concept. ${ }^{8}$ A large number of studies have dealt with the relationship between body image and self-concept and psychological variables. Some studies revealed the relationship between body image and societal perfectionism and internalization of social messages, the need to hide perceived flaws from others, perfectionism, and psychological damages. ${ }^{9-12}$

Several studies indicated the relationship between self-concept and social functioning, individual goal orientation and the demand for cosmetic surgery. ${ }^{13-15}$ Here, the impact of cosmetic surgery on marital satisfaction and self-concept as probable factors affecting the demand for cosmetic surgery has been assessed. Investigating this issue is necessary to determine clinical features of this specific population in order to prevent unnecessary surgery leading to postoperative adverse outcomes.

\section{MATERIALS AND METHODS}

The study population is consisted of married women who had or requesting for cosmetic surgery from January $1^{\text {st }}, 2015$ to June $6^{\text {th }}, 2015$. Inclusion criteria were consent and cooperation. The surgery date was specified by plastic surgeon after passing medical procedures and having no facial cosmetic surgery and medical and urgent reasons to perform cosmetic surgery for applicants. Exclusion criteria were having no diagnosable mental disorder as well as not having cosmetic surgery on one body organ for the second time. The control group was non-applicants who were selected from the volunteers' relatives. The research sample was consisted of 44 individuals who had facial cosmetic operation, 51 individuals requesting for cosmetic surgery and 55 were control as nonapplicants from general population.

Instruments that were used included (i) ENRICH Marital Satisfaction Questionnaire. The scale was developed before to assess potentially problematic areas and areas of strengths and in marital relations. ENRICH Questionnaire contains 12 subscales as follows: Idealistic distortion, marital satisfaction, personality issues, communication, conflict resolution, financial management, leisure activities, intercourses, children, parenting, family and friends, egalitarianism roles and religious orientation. This questionnaire is composed of strong psychometric properties. ${ }^{15}$ Olson et al. ${ }^{16}$ estimated the internal consistency of this questionnaire from 0.73 to 0.90 .

(ii) Rogers' Self-concept inventory developed in 1951 was a determinant of individuals' positive and negative self-concept. The time required to answer this test was approximately 
20 minutes. It is an objective test and is consisted of a 7-score level assigned between two features and one is supposed to select one of the numbers between the two features. This test has A and B forms. During the presentation of Form A, the participants were asked to mark a number based on the given scale (ranging from one to seven based on closeness to the supposed feature). Then, the participants were asked to specify their ideal personal traits in the Form B. The calculated scores between 0-7 and 7 and above indicate normal and negative/weak self-concept, respectively. In other words, high scores obtained for this scale show a mismatch between the actual self and the ideal self.

Pasha et al. ${ }^{17}$ in their study reported the reliability of this scale using split-half method and Cronbach's alpha can be 0.79 for the Form $\mathrm{A}$ and 0.55 for the Form B, generally indicating acceptable values. Raghibi et al. ${ }^{18}$ showed that the Cronbach's alpha values were estimated between 0.69 and 0.60 for the Form A and Form $\mathrm{B}$, respectively. In order to analyze the data, descriptive statistics as well as one-way analysis of variance (ANOVA) and multivariate analysis of variance (MANOVA) were run with the SPSS software (version 21, Chicago, IL, USA).

\section{RESULTS}

Forty $(85 \%)$ women underwent cosmetic surgery, $32(80 \%)$ of women looked for cosmetic surgery, and $39(86 \%)$ were control group with academic education. Moreover, the data revealed that the age range in $16(34 \%)$ women undergoing cosmetic surgery, 19 (46.3\%) women seeking cosmetic surgery and $21(46.7 \%)$ of women of control group were between 21 and 40 years. Also, 26 (55.3\%) women who had cosmetic surgery, 18 (43.9\%) women seeking cosmetic

Table 1: Results of ANOVA on mean marital satisfaction components.

\begin{tabular}{|c|c|c|c|c|c|}
\hline Variable & Source & df & Mean Square & $\mathbf{F}$ & P value \\
\hline \multirow[t]{3}{*}{ Personality Issues } & Between Groups & 2 & 4.718 & 6.589 & $<0.001^{*}$ \\
\hline & Within Groups & 147 & 0.716 & & \\
\hline & Total & 149 & & & \\
\hline \multirow[t]{3}{*}{ Communication } & Between Groups & 2 & 2.655 & 3.664 & $0.02 *$ \\
\hline & Within Groups & 147 & 0.724 & & \\
\hline & Total & 149 & & & \\
\hline \multirow[t]{3}{*}{ Conflict Resolution } & Between Groups & 2 & 4.610 & 8.095 & $<0.001 *$ \\
\hline & Within Groups & 147 & 0.570 & & \\
\hline & Total & 149 & & & \\
\hline \multirow[t]{3}{*}{ Financial Management } & Between Groups & 2 & 2.419 & 3.778 & $0.02 *$ \\
\hline & Within Groups & 147 & 0.640 & & \\
\hline & Total & 149 & & & \\
\hline \multirow[t]{3}{*}{ Leisure Activities } & Between Groups & 2 & 3.862 & 5.667 & $<0.001 *$ \\
\hline & Within Groups & 147 & 0.682 & & \\
\hline & Total & 149 & & & \\
\hline \multirow[t]{3}{*}{ Sexual Relationship } & Between Groups & 2 & 2.096 & 1.769 & 0.17 \\
\hline & Within Groups & 147 & 1.184 & & \\
\hline & Total & 149 & & & \\
\hline \multirow[t]{3}{*}{ Children and Parenting } & Between Groups & 2 & 0.212 & 0.483 & 0.61 \\
\hline & Within Groups & 147 & 0.438 & & \\
\hline & Total & 149 & & & \\
\hline \multirow[t]{3}{*}{ Family and Friends } & Between Groups & 2 & 2.094 & 4.449 & $0.01 *$ \\
\hline & Within Groups & 147 & 0.471 & & \\
\hline & Total & 149 & & & \\
\hline \multirow[t]{3}{*}{ Religious Orientation } & Between Groups & 2 & 0.904 & 1.604 & 0.20 \\
\hline & Within Groups & 147 & 0.563 & & \\
\hline & Total & 149 & & & \\
\hline \multirow[t]{3}{*}{ Overall marital satisfaction } & Between Groups & 2 & 2.146 & 6.424 & $<0.001^{*}$ \\
\hline & Within Groups & 147 & 0.334 & & \\
\hline & Total & 149 & & & \\
\hline
\end{tabular}

\footnotetext{
*Indicates that value is statistically significant
} 
surgery and $21(46.7 \%)$ women of control group were 41 years of age and older. The mean age of women in operated group, applicants seeking for surgery, and control group were $42.26 \pm 5.77$, $39.58 \pm 6.63$, and $40.91 \pm 5.6$ yeas, respectively.

According to the variance analysis results shown in Table 1, significant differences were observed among the subjects in the three groups of undergoing surgery, applicant for operation and control in terms of all the marital satisfaction components except for the components of sexual relations, marriage, children, and religious orientation. Furthermore, the three groups were significantly different in terms of the total marital satisfaction score $(p<0.001)$.

As shown in Table 2, the surgery group and the applicant group for operation were significantly different from each other in terms of the adjusted marital satisfaction mean scores; this means that the participants in the applicant group reported higher marital satisfaction. Moreover, the adjusted mean scores of the marital satisfaction components were significantly different in the applicant group, as compared with both the surgery and control group, while, the applicant subjects reported higher satisfaction in majority of the components.

Accordingly, the applicant group reported higher satisfaction than the surgery and control group in terms of the personality issues component, higher satisfaction than the control group regarding communication component, higher satisfaction than the surgery and control group regarding conflict resolution and leisure activities components, and higher satisfaction than the surgery group in terms of the

Table 2: Results of comparison of pairs of adjusted means of the marital satisfaction components at the group level using Tukey's test between the group seeking and undergone for cosmetic surgery and the non-applicant control group.

\begin{tabular}{|c|c|c|}
\hline Components of marital satisfaction & Groups & P value \\
\hline \multirow[t]{3}{*}{ Personalit issues } & Requesting vs. undergone for cosmetic surgery & $0.01 *$ \\
\hline & Non-applicants vs. undergone for cosmetic surgery & 0.89 \\
\hline & Non-applicants vs. requesting for cosmetic surgery & $<0.001 *$ \\
\hline \multirow[t]{3}{*}{ Communication } & Requesting vs. undergone for cosmetic surgery & 0.11 \\
\hline & Non-applicants vs. undergone for cosmetic surgery & 0.90 \\
\hline & Non-applicants vs. requesting for cosmetic surgery & $0.03 *$ \\
\hline \multirow[t]{3}{*}{ Conflict resolution } & Requesting for cosmetic surgery vs. who had surgery & $<0.001 *$ \\
\hline & Non-applicants vs. who had surgery & 0.85 \\
\hline & Non-applicants vs. requesting for cosmetic surgery & $<0.001 *$ \\
\hline \multirow[t]{3}{*}{ Financial management } & Requesting vs. undergone for cosmetic surgery & $0.02 *$ \\
\hline & Non-applicants vs. undergone for cosmetic surgery & 0.53 \\
\hline & Non-applicants vs. requesting for cosmetic surgery & 0.18 \\
\hline \multirow[t]{3}{*}{ Leisure activities } & Requesting vs. undergone for cosmetic surgery & $0.03 *$ \\
\hline & Non-applicants vs. who had surgery & 0.90 \\
\hline & Non-applicants vs. requesting for cosmetic surgery & $<0.001^{*}$ \\
\hline \multirow[t]{3}{*}{ Sexual relationship } & Requesting for cosmetic surgery vs. who had surgery & 0.81 \\
\hline & Non-applicants vs. undergone for cosmetic surgery & 0.48 \\
\hline & Non-applicants vs. requesting for cosmetic surgery & 0.15 \\
\hline \multirow[t]{3}{*}{ Children and parenting } & Requesting for cosmetic surgery vs. who had surgery & 0.60 \\
\hline & Non-applicants vs. undergone for cosmetic surgery & 0.76 \\
\hline & Non-applicants vs. requesting for cosmetic surgery & 0.95 \\
\hline \multirow[t]{3}{*}{ Family and friends } & Requesting vs. undergone for cosmetic surgery & $0.01 *$ \\
\hline & Non-applicants vs. who had surgery & 0.48 \\
\hline & Non-applicants vs. requesting for cosmetic surgery & 0.13 \\
\hline \multirow[t]{3}{*}{ Religious orientation } & Requesting vs. undergone for cosmetic surgery & 0.17 \\
\hline & Non-applicants vs. undergone for cosmetic surgery & 0.61 \\
\hline & Non-applicants vs. requesting for cosmetic surgery & 0.63 \\
\hline \multirow[t]{3}{*}{ Overall marital satisfaction } & Requesting vs. undergone for cosmetic surgery & $<0.001 *$ \\
\hline & Non-applicants vs. undergone for cosmetic surgery & 0.98 \\
\hline & Non-applicants vs. requesting for cosmetic surgery & $<0.001 *$ \\
\hline
\end{tabular}

*Indicates that value is statistically significant 
financial management and family and friends' components. Expectation of positive outcomes in the applicant group after cosmetic surgery had a positive impact, although can be transient, on the marital satisfaction components.

Table 3 demonstrates that significant differences were observed among the subjects in the three groups for ideal self-concept and overall self-concept score; however, these groups were observed to be similar regarding the actual self-concept score. Therefore, various levels of self-concept can be concluded in people undergoing cosmetic surgery, surgery applicants and ordinary people. As revealed in Table 4, no significant difference was observed in the adjusted real self-concept mean scores between the three groups of operated, surgery applicant and the control.

Regarding ideal self-concept, however, a significant difference was noted in the surgery group when compared to the control group. Moreover, regarding the final self-concept score, resulting from the difference between real and ideal self-concept, the control group demonstrated higher positive self-concept compared to other groups. Hence, lower selfconcept score indicates a positive self-concept, so the difference between the real and ideal selfconcept in the normal group was less than the other two groups.

\section{DISCUSSION}

Findings from this study revealed that the groups were significantly different in terms of marital satisfaction. Accordingly, marital satisfaction was higher in the surgery applicant and operated group in comparison to the control group, indicative of the impact of cosmetic surgery on marital satisfaction. In addition, based on marital satisfaction components results, the subjects in the three groups were significantly different in terms of all the marital satisfaction components except for the components of sexual relations, marriage, children, and religious orientation.

This means that the subjects in the surgery applicant group reported higher satisfaction in most of the components. Accordingly, this

Table 3: Results of ANOVA on the mean score of actual self-concept, ideal self-concept and self-concept.

\begin{tabular}{llllll}
\hline Variable & Source & df & Mean Square & F & P value \\
\hline Real self-concept & Between Groups & 2 & 74.228 & 0.713 & 0.49 \\
& Within Groups & 147 & 104.078 & & \\
& Total & 149 & & & \\
Ideal self-concept & Between Groups & 2 & 453.152 & 4.089 & $0.01^{*}$ \\
& Within Groups & 147 & 110.811 & & \\
Self-concept & Total & 149 & & & \\
& Between Groups & 2 & 597.420 & 9.147 & $<0.005^{*}$ \\
& Within Groups & 147 & 65.310 & & \\
\hline
\end{tabular}

*Indicates that value is statistically significant.

Table 4: Results of comparison of pairs of adjusted means of actual self-concept, ideal self-concept and selfconcept at the group level using Tukey's test.

\begin{tabular}{lll}
\hline $\begin{array}{l}\text { Components of marital } \\
\text { satisfaction }\end{array}$ & Groups & P value \\
\hline Real Self-concept & Requesting for cosmetic surgery vs. undergone for cosmetic surgery & 0.58 \\
& Non-applicants vs. undergone for cosmetic surgery & 1.0 \\
& Non-applicants vs. requesting for cosmetic surgery & 0.53 \\
Ideal Self-concept & Requesting for cosmetic surgery vs. undergone for cosmetic surgery & 0.50 \\
& Non-applicants vs. undergone for cosmetic surgery & $0.01^{*}$ \\
& Non-applicants vs. requesting for cosmetic surgery & 0.19 \\
Self-concept & Requesting for cosmetic surgery vs. undergone for cosmetic surgery & 0.97 \\
& Non-applicants vs. undergone for cosmetic surgery & $<0.001^{*}$ \\
& Non-applicants vs. applying for cosmetic surgery & $<0.001^{*}$ \\
\hline
\end{tabular}

*Indicates that value is statistically significant 
applicant group reported higher satisfaction than the operated and control group regarding the personality issues, conflict resolution and leisure activities components, and with higher satisfaction than the control group in terms of the communication component, and a higher satisfaction than the operated group regarding the financial managemen, family and friends components.

These findings are consistent with the results of the study by Tavassoli et al. on the effects of cosmetic surgery on marital satisfaction. The participating women in their study regarded the cosmetic surgery-induced beauty as contributing to greater self-confidence, greater success in married life and higher social status and prestige, as well as a factor to reach power in the family. They showed that, according to Giddens in this sense, human body turns into a place to create and fulfill people's wishes and aspirations. ${ }^{19}$

Also, the results of this study are in line with the findings of the study by Nikolic et al. on motivational factors influencing demand for breast surgery. They showed that the subjects reported a greater sense of femininity, higher attractiveness, less feeling of shame in the presence of men, improved sexual life, and facilitated finding of partners as important motivational factors considered in demand for cosmetic surgery. ${ }^{20}$ In this context, the findings of this study are consistent with the results of Swami et al. too. ${ }^{21}$ Accordingly, they examined the relationship between requesting for cosmetic surgery and perfectionism, appearance schemas, satisfaction with romantic styles and relations and suggested that the demand for cosmetic surgery can be predicted based on the dimensions perfectionism, appearance schemas and relation satisfaction. $^{21}$

The findings of this research study are identical to the results emphasizing the importance of psychosocial factors, ${ }^{5,22,23}$ and the interaction between psychosocial factors and psychological variables affecting the demand for cosmetic surgery. The results of this study are similar to the McNulty et al.'s findings showing that physical attractiveness plays an important role in romantic relations even after initiating a relation. ${ }^{24}$ According to our results, it was shown that planning for cosmetic surgery and, more precisely, the applicants' expectations for the positive outcome of the cosmetic surgery can have a positive impact on the marital satisfaction.
Our findings showed a statistically significant difference between the operated and surgery applicant and the control groups. The subjects in these two groups received higher self-concept scores. Since the higher self-concept scores reflect the weaker self-concept, the control group had higher levels of self-concept. The results of our study also showed no significant difference in real self-concept scores of the three groups including surgery applicants, operated and control groups. Regarding the ideal self-concept, the results showed that the ideal self-concept was higher in surgery group than the control group and the difference was statistically significant.

According to the results, it was demonstrated that one of the main reasons explaining individuals' tendency towards cosmetic surgery may be the applicant's low selfconcept. Therefore, the second hypothesis of this study was confirmed. Similarly, it was shown that people who had cosmetic surgery possessed a body image weaker than those who had no interest in cosmetic surgeries. ${ }^{25}$ More specifically, overweight individuals were more interested in liposuction cosmetic surgery and had a body image weaker than the others. ${ }^{25}$

In this regard, the results of this study are in line with the findings of Swami et al. They found a significant relationship between gender and age with acceptance of cosmetic surgery. ${ }^{21}$ This relationship can be explained by mediating variables including personality, self-esteem, conformity and physical attractiveness. These results provide a preliminary model integrating personality traits and individual differences in predicting the acceptance of cosmetic surgery. ${ }^{21}$

On the other hand, the results of this study indicated the lack of cosmetic surgery effect on self-concept in women who had cosmetic surgery are not identical with the findings obtained by Soest et al. ${ }^{26}$ In their research, they investigated the impacts of plastic surgery on body image, self-esteem and psychological problems prior to and 6 months after performing plastic surgery and found significant improvement in postoperative body image (satisfaction with physical appearance) of the experimental group. ${ }^{26}$ In this regard, it was suggested that individuals reported a better body image after cosmetic surgery procedures.

According to the results of our study, it can be concluded that the people who had cosmetic surgery as well as being cosmetic 
surgery applicants in comparison with general population have lower levels of self-concept. These finding have implications for a lot of cosmetic surgery psychiatrists, psychologists, counselors and specialists. Undoubtedly, the identification of psychological factors related to the demand for cosmetic surgery procedures prevents the possible negative consequences of actions induced by psychological factors but not medical necessity.

\section{CONFLICT OF INTEREST}

The authors declare no conflict of interest.

\section{REFERENCES}

1 Hwang PH. Surgical Rhinoplasty: recent advances and future direction. Otolaryngol Clin North Am 2004;37:489-99

2 Mulkens S, Jansen A. Changing appearances: Cosmetic surgery and body dysmorphic disorder. Neth J Psychol 2006;61:34-41.

3 American Society for Aesthetic Plastic Surgery. 2008. Quick facts: Highlights of the ASAPS 2007 statistics on cosmetic surgery. Available from; http://www.sciencedirect. com.

4 Azizi, M, Mahroozadeh, S, Nik Ravanfar, N. Ethical issues in cosmetic surgery. Iranian $J$ Med Ethics History 2008;1:25-34.

5 Brown A, Furnham A, Glanville L, Swami V. Factors that affect the likelihood of undergoing cosmetic surgery. Aesthet Surg $J$ 2007;27:501-8.

6 Bong M, Skaalvik EM. Academic selfconcept and self-efficacy: how different are they really? Educ Psychol Rev 2003;15:1-40

7 Kaiser SB. The social psychology of clothing: Symbolic appearances in context ( $2^{\text {nd }} e d .$, rev. $)$. New York: Fairchild Publications. 1997.

8 Robinson RT. Clothing Behavior, Body Cathexis, and Appearance Management of Women Enrolled in a Commercial Weight Loss Program. Partial fulfillment of the requirements for the degree of Doctor of Philosophy in Clothing and Textiles, Blacksburg, Virginia. 2003.

9 Grammas DL, Schwartz JP. Internalization of messages from society and perfectionism as predictors of male body image. Body Image 2009;6:31-6.

10 Sherry SB, Vriend JL, Hewitt PL, Sherry
DL, Flett GL, Wardrop AA. Perfectionism dimensions, appearance schemas, and body image disturbance in community members and university students. Body Image 2009:6:83-9.

11 Welch E, Miller JL, Ghaderi A, Vaillancourt T. Does perfectionism mediate or moderate the relation between body dissatisfaction and disordered eating attitudes and behaviors? Eating Behav 2009;10:168-75.

12 Ackard DM, Croll JK, Kearney-Cooke A. Dieting frequency among college females: Association with disordered eating, body image, and related psychological problems. J Psychosom Res 2002;52:129-36.

13 Brandt YH. The relation between self-concept and social functioning in adolescence. $J$ Adolesc 2008;31:1-16.

14 Poulsen AA, Ziviani JM, Cuskelly M. General self-concept and life satisfaction for boys with differing levels of physical coordination: The role of goal orientations and leisure participation. Hum Mov Sci 2006;25: 839-60.

15 Pasha Gh, Naderi F, Akbari SH. Comparison of body image, body mass index, overall health and self-concept among individuals having cosmetic surgery, cosmetic surgery applicants and ordinary people in Behbahan. New Find Psychol 2009;2: 61-80.

16 Arnold V, Min D. Empowering couples program for married couples. Marriage Fam $J$ 2004; 7:237-53.

17 Olson DH, Olson AK. Prepare/enrich program. In R. Berger, and M. Hannah (Eds.), Handbook of preventative approaches in couple therapy. New York: Brunner/Mazel Inc. 1999; pp. 196-216.

18 Raghibi M, Minakhani GHR. On the relationship between body control, body image and self-concept. Knowledge Res Appl Psychol 2010;4:72-81.

19 Tavassoli GHA, Modiri F. Women's Tendency towards cosmetic surgery in Tehran. Sciopsychol Stud Women 2011;10:61-82.

20 Nikolic J, Janjic Z, Marinkovic M, Petrovic J, Bozic T. Psychosocial characteristics and motivational factors in woman seeking cosmetic breast augmentation surgery. Vojnosanitetski Pregled 2013;70:940-6.

21 Swami V, Mammadova A. Associations between consideration of cosmetic surgery, perfectionism dimensions, appearance schemas, relationship satisfaction, excessive 
reassurance-seeking, and love styles. Indivd Differ Res 2012;10: 81-94.

22 Crockett RJ, Pruzinsky T, Persing JA. The influence of plastic surgery 'reality TV' on cosmetic surgery patient expectations and decision making. Plast Reconstr Surg 2007;120:316-24.

23 Sperry S, Thompson JK, Sarwer DB, Cash TF. Cosmetic surgery reality TV viewership: Relations with cosmetic surgery attitudes, body image, and disordered eating. Ann Plast Surg 2009;62:7-11.

24 McNulty JK, Neff LA, Karney BR. Beyond initial attraction: Physical attractiveness in newlywed marriage. J Fam Psychol 2008;22:135-43.

25 Fredrick DA, Lever J, Peplau J, Letita A. Intrest in cosmetic Surgery and body image: view of man and woman across the lifespan. Plastic Reconstr Surg 2007;120:1047-415.

26 Soest T, Kvalem IL, Roald HE, Skolleborg KC. The Effects of Cosmetic Surgery on Body Image, Self-Esteem, and Psychological Problems. J Plast Reconstr Aesthet Surg 2009;62:1238-44. 